
Participation, Health, and Policy in Canada

\author{
Janice Forsyth \\ Director of the International Centre for Olympic Studies, Western University
}

aboriginal policy studies Vol. 3, no. 1\&2, 2014, pp. 214-222

This article can be found at:

http://ejournals.library.ualberta.ca/index.php/aps/article/view/21707

ISSN: $1923-3299$

Article DOI: http://dx.doi.org/10.5663/aps.v3i1-2.21707

aboriginal policy studies is an online, peer-reviewed and multidisciplinary journal that publishes original, scholarly, and policy-relevant research on issues relevant to Métis, non-status Indians and urban Aboriginal people in Canada. For more information, please contact us at apsjournal@ualberta.ca or visit our website at www.ualberta.ca/nativestudies/aps/.

UNIVERSITY OF ALBERTA

FACULTY OF NATIVE STUDIES
Aboriginal Affairs and

Affaires autochtones et Développement du Nord Canada 


\section{Aboriginal Sport in the City: Implications for Participation, Health, and Policy in Canada}

Janice Forsyth

Director of the International Centre for Olympic Studies, Western University

\section{The Optics of Aboriginal Participation in Sport}

The 2014 Olympic Games in Sochi, Russia have just ended, and I'm taking a moment to reflect on a pattern I've noticed over the past several Games. As the Director of the International Centre for Olympic Studies at Western University in London, Ontario, it's my job to watch the Games as they unfold in real time and to provide media with commentary and insight on whatever producers deem to be newsworthy items. Well, I don't really "watch" the Games so much as I follow news about them, mostly online, and monitor the trends in reporting. It's my responsibility to influence the type of information that gets relayed to the public by educating journalists on the issues behind their stories. For instance, the estimated $\$ 3$ billion USD that Putin spent on security for the 2014 Olympic and Paralympic Games to minimize the threat of terrorism also helps to legitimize the control of civilians by making sure peaceful protestors don't disrupt the biggest party in the world by inserting non-sporting narratives, like Native rights and $\mathrm{LGBTQ}^{1}$ issues, into the public realm. The increased use of advanced surveillance systems and military force to control the public at the Olympic Games is a new phenomenon, and a frightening one at that, for the way people appear to be willing to give up important freedoms in exchange for a massive celebration organized around athletic competitions that leave mostly unused venues and huge public debt in their place. Most journalists understand these patterns when they are given an opportunity to discuss and digest them, but claim there are limitations to what they can say or write, especially if they are working for Olympic broadcasters, which go heavy on sports reporting and light on analysis. All too often, commercial interests trump the need for information.

A similar pattern of reporting can be found in media on Canadian Aboriginal athletes in Olympic Games over the years, where there is a tendency to gloss over important issues and homogenize their sporting experiences. Usually these stories emphasize their struggles to get involved and stay involved in sport, and touch on issues of discrimination while focusing on their achievements in the mainstream, which reinforces the idea that mainstream sport is the best and most appropriate way to do sport. Rarely do these accounts go into any detail about the varied socio-economic backgrounds of Aboriginal athletes, the diverse geographies that structure their opportunities for sport, the role of gender in family and community life, and what this means for male and female participation-or even how appearance and self-identification pave the way for Aboriginal athlete acceptance into

1 Lesbian-Gay-Bisexual-Transgendered-Queer.

aboriginal policy studies, vol. 3, no. 1\&2, 2014 
mainstream clubs and teams. Even less frequent are stories about disability and Aboriginal sport. If media reports are taken as one measure of "what we know" about Aboriginal athletes in sport, then we have a very narrow understanding of their experiences in Canada, and this lack of understanding and awareness has important policy implications for sport and recreation, health, and education, to name a few key sectors.

To return briefly to the 2014 Olympic Games in Sochi, I received several requests from journalists to discuss the significance of Carey Price being named the starting goalie for the Canadian men's hockey team in Russia (Price is a member of the Ulkatcho First Nation in British Columbia). I explained that his position on the team is much more than recognition of his hockey talent; it symbolizes Canadian Aboriginal success in the mainstream. Of course it helps that he plays hockey, the quintessential Canadian sport for boys and men, and one of the most anticipated events in the Winter Games. Yet, Aboriginal achievements are so rarely embraced in the national imaginary that Price's story stands out as a source of pride for all Canadians, as well as an important reminder of the myriad hurdles that Aboriginal athletes face trying to reach their sporting dreams.

In discussing those hurdles, the journalists were generally of the opinion that most Aboriginal people live in rural or remote areas and are economically poor. They saw those two factors, along with racism, as the primary reasons why there are so few successful athletes like Price in the Canadian sport system. We examined those assumptions by talking about how Price grew up in Anahim Lake, a small ranching community nestled in the Coast Mountains of British Columbia, about 860 kilometers northeast of Vancouver, and that that distance was a real challenge for anyone who wanted to do elite sport. We also talked about how his family appeared to possess the economic and cultural capital to advance his career in sport: his father is a pilot and former semi-professional hockey player, while his mother is a former Chief of the Ulkatcho First Nation. In other words, his parents were able to help finance his involvement in hockey, possessed the knowledge to ease his transition into elite sport, and even provided occasional air transportation for his training and competition. That is not the normal sporting biography of most Aboriginal youth in Canada.

Perhaps, then, stories about elite Aboriginal athletes like Price can be used as jumpingoff points to engage in dialogues about the complex challenges that different groups of Aboriginal people face. There is almost no information about urban Aboriginals, for example, who comprise more than half of the total Aboriginal population in Canada (Aboriginal Affairs and Northern Development Canada 2010). So far, my experience responding to media for two Olympic Games where Canadian Aboriginal athletes have received attention (Vancouver 2010 and Sochi 2014) is that media are reluctant to delve into problems that complicate popular understandings about Aboriginal lives in Canada.

\section{Aboriginal Participation in Canadian Sport: What the Statistics Tell Us}

Before we turn to Aboriginal sport in the city, it's important to clarify what "sport" means to government, because it has important policy implications. Sport Canada, the federal 
agency that oversees sport development in Canada, defines "sport" as a competitive activity between two or more participants that requires specialized neuromuscular and cardiovascular skills, has clearly defined rules and regulations, provides opportunities to advance competitively, and has a governing body that oversees its administrative growth worldwide (Canadian Heritage 2013a). This means the federal government does not consider activities like walking, jogging, powwow dancing, snowmobiling, street hockey, skateboarding, and many other cultural and recreational pursuits that Aboriginal people enjoy, to be fundable activities as defined by Sport Canada. Furthermore, these non-fundable activities are not usually counted in surveys on sports participation, which skews our overall perspective on the health of the nation, and not just of Aboriginal people.

What statistics are collected about Aboriginal sport in Canada? The short answer is none, which means policies and programs are being implemented in the absence of reliable data. This raises troubling questions about how government and service organizations decide whether the limited resources they have are being used effectively (Forsyth and Paraschak 2013). Little has been written about this issue and its implications for other sectors linked to sport, such as health, education, justice, and economic development. In most cases, policy makers, program managers, and advocates for Aboriginal sport rely on anecdotal evidence and data collected from broader policies and programs that were not intended to address Aboriginal issues specifically.

This problem is not limited to Aboriginal people. There is a dearth of information about sports participation among Canadians generally. At present, there are three ongoing surveys that gather data on the physical activity involvement of Canadians: the National Population Health Survey, by Health Canada; the Physical Activity Monitor, by the Canadian Fitness and Lifestyle Research Institute; and the General Social Survey on Time Use (Sport Supplement), by Statistics Canada. Of those three, only the General Social Survey on Time Use can be used to examine baseline data for sports participation, since it is the only survey that collects data on sport. The other two surveys deal with the broader range of physical activities (Sutcliffe 2002), such as those mentioned above. In other words, data from the National Population Health Survey and the Physical Activity Monitor cannot be used to address questions about sports participation. As well, the General Social Survey on Time Use excludes residents of Yukon, Nunavut, and the Northwest Territories, where Aboriginal people comprise a large portion of the population, thus ignoring sport participation trends in the far northern regions of the country (Ifedi 2008, 8).

Two other popular data sources that are often used to round out the current picture of sports participation in Canada are Kids' Sport, a report compiled for Statistics Canada that used data from the 1992 and 2005 General Social Survey on Time Use to examine trends in organized sports participation of children aged 5 to 14 (Clark 2008), and Strengthening Canada: The Socio-Economic Benefits of Sport Participation in Canada, which was a report compiled for the Conference Board of Canada and based on data from a literature review and national survey conducted by the board (Bloom, Grant, and Watt 2005). While these three sources (Kids' Sport, General Social Survey on Time Use, and Strengthening Canada) provide baseline data for Canadians generally, none account for Aboriginal participation in sport. 
Several important policy documents acknowledge the lack of statistical data for Aboriginal sport development in Canada. For instance, it was identified as a key weakness in the Federal-Provincial/Territorial Priorities for Collaborative Action in both the 2002-2005 and 2007-2012 funding periods (Canadian Heritage 2013b), as well as in Sport Canada's Policy on Aboriginal Peoples' Participation in Sport (Canadian Heritage 2005, 7). The lack of data is a problem because, without clear reference points for tracking issues and patterns over time (e.g., rates of Aboriginal participation in various sports), it is impossible to know whether a policy or an intervention is meeting its stated objectives. I will return to this last point after the next section.

\section{Urban Sporting Opportunities: More Fantasy than Reality}

The lack of baseline data is compounded by a common misconception that there are more, and more affordable, opportunities for sport in urban areas. While this is true to some degree because competitive, organized sport usually requires the types of resources found in cities-from specialized facilities to high quality equipment and certified coaching, as well as a broad range of sport sciences to assist with athlete development-it is mostly individuals and families from middle- and upper-class backgrounds who can afford to engage in sport on a regular basis (Coakley and Donnelly 2009, 310). With many urban Aboriginal people struggling to make ends meet financially, finding the time and money to engage in sport is a luxury (Forsyth and Heine 2008, 103-105). Being in a city means being close to where sport happens, but it does not mean that everyone is equally able to take advantage of the so-called "opportunities" that urban areas offer.

A related problem is the myth that sport is a meritocracy, where talented participants will somehow rise to top because of their perseverance and dedication. This myth blinds us to the ways that class dynamics have always been entrenched in sport (Morrow and Wamsley 2013, 78-123). This class-based trend began in the late 1800s, when new developments in transportation, communication, and mechanization stemming from the Industrial Revolution ushered the impromptu games and pastimes of the masses into a system of organized sports that catered to the interests of the economic elite. For instance, the invention and widespread use of the steamship and the completion of the railroad during this era meant people were able to travel farther, faster for competitions. However, the high fees associated with these modes of transportation meant only those who could afford the tickets could take advantage of the opportunities sport offered. Furthermore, with this new organized approach to sport came a real need to facilitate its development throughout the country. Facilities had to be built, games promoted, players and teams compensated for their expenses (despite the pretense of amateurism), leagues and clubs established, governing bodies created, and spectator comfort addressed (Morrow and Wamsley 2013, 47-52). All of this required significant resources from the participants. So, from the very beginning, sport was never meritocratic. It was founded on and reproduced class-based interests. 
In recent years, the upward trend in costs can be explained by the ongoing professionalization of sport, where even parents of children enrolled in community sport programs expect certified coaches, sport specific facilities, the latest technology and equipment, and access to other programs aimed at enhancing their child's advancement in sport (Gruneau 2010). The professionalization of sport is itself is a response to increasing government demands for Canadian athletes to achieve better results in international competitions. During the 1970s, Canada's poor performances at the Olympic Games, especially in hockey, led the federal government to place more emphasis on winning and investing in more strategic ways that would bring home medals (MacIntosh and Whitson 1990). This trend intensified after Canada hosted the 1988 Winter Olympic Games in Calgary, where Canadian athletes failed again to bring home any gold medals (the first time being the 1976 Olympic Games in Montreal), resulting in a shameful distinction: Canada was the only country in Olympic history (summer or winter) to not win a gold medal on home soil. Since 2006, the federal government has spent more than one billion dollars on elite sport development, leading to the emergence of a new crop of organizations like Own the Podium to help Canadian athletes win medals at Olympic Games (Tewksbury and Arsenault 2014). Sporting excellence on the international stage is important because of the messages it conveys to the world about a nation's social, political, and economic strength. Sport is never about athletic prowess alone; there are always broader meanings attached to the outcomes of sport that go well beyond the podium. The federal government and its allied agencies are unapologetic about this intensive focus on winning and pour significant public resources into already successful athletes and teams, leaving the others to fend for themselves in an environment where more resources are going to fewer athletes and less sports. Nearly every facet of sport, including who can afford to take advantage of those opportunities, has been impacted by professionalization.

The new focus on winning has eroded the traditional pyramid structure for sport, which was characterized by a large number of participants at the base and a much smaller group of elite athletes at the top. With more resources going to fewer people, the pyramid no longer exists. And because many of the people who remain involved in sport tend to possess wealth and power, their values and preferences for sport are the ones that get reproduced on the national and international stage, reinforcing social and class inequalities in sport (Coakley and Donnelly 2009, 311).

The myth of the city as the place where sport happens, combined with the idea that sport is meritocratic, is problematic because it reinforces the belief that people who do not participate in sport choose not to do so. From this point of view, the individual or family makes a "lifestyle choice" to opt in or out of programs whenever they feel like it, rather than being marginalized or forced out of sport because of structural conditions that make participation almost impossible. Furthermore, this "lifestyle" approach means that policies and programs do not need to focus on structural issues because people are thought to be opting out of sport, when, in reality, the opportunity never existed for them in the first place. 


\section{Aboriginal Sport in the City: The Picture and Policy Implications}

What types of sporting opportunities are available to urban Aboriginals? And what do these opportunities look like? For Aboriginal youth, school-based programs hold some promise, though there is still much room for improvement (Halas, McRae, and Carpenter 2013). For instance, high school students sometimes have to learn the fundamental skills just to play a game, let alone enable their enjoyment in sport. Learning these skills in school is sometimes the only way to obtain them, as they cannot afford a club membership, private coaching lessons, or even the user-pay fees that some public recreation programs require just to stay afloat financially. As well, teachers might need to be educated about the different issues that affect Aboriginal children and youth and their families, and find creative ways to facilitate student involvement rather than alienating them because their living circumstances don't fit the "proper" expectations for sport, such as providing an after-school child care service for participants who require this kind of support on a regular basis. There is also the issue of teacher training: many physical education programs in Canada emphasize middle-class values and approaches to sport, which may not always fit the types of resources or attitudes towards sport that are common in inner-city areas (Halas, McRae, and Carpenter 2013, 193). Indeed, Aboriginal students may choose to engage in physical practices other than sport, which renders inoperative any discussion about barriers to sports participation or the marginalization of Aboriginal youth from the mainstream sports system (Forsyth and Heine 2008, 9).

For Aboriginal girls and women, there appear to be even fewer opportunities for sports participation, especially as athletes. Here, ideas about gender come into play, so that girls and women might find themselves more responsible than boys and men for providing care-giving duties to their family. Ideas about a woman's "proper" place in society connects to these family demands, legitimizing their decision to stay home or on the sidelines while boys and men engage in sport (Paraschak and Forsyth 2010,171) and reap the benefits their involvement provides. The under-representation of Aboriginal girls and women in sport has been acknowledged in various reports, which led to the insertion of a brief statement about Aboriginal girls and women having "unique" needs in Sport Canada's Policy on Aboriginal People's Participation in Sport (Paraschak and Forsyth 2011, 217). These "unique" needs were not defined, leaving readers guessing about what these needs were and how they could be addressed.

What about the link between sports participation and health? While it is true that lower social classes have on average more health problems than people in higher-class categories, there is no evidence to suggest lower social classes are less physically active than their richer counterparts. That might be a heretical statement to make in light of the dizzying array of health problems that Aboriginal people face, including those in urban areas. However, most sport and physical activity surveys are based on middle-class assumptions about whitecollar sedentary jobs, which presume that people who do not go to the gym or engage in some type of organized sport or recreation are inactive. Contrast this with the daily life of the working class, who expend enormous amounts of energy working in manual or domestic 
labour (Coakley and Donnelly 2009, 312). Baseline data about Aboriginal participation in sport, as well as recreation and leisure, are badly needed so that we can better understand the challenges that Aboriginal people face in gaining access to and staying involved in sport-if indeed that is the route they choose to go.

I return now to media reports about Aboriginal athletes in Olympic Games. It is easy to read these stories for the feel-good effect they have on our collective imagination. Their stories are uplifting because they follow a traditional narrative arc that emphasizes struggle over adversity; they are educational because they show us how the struggles of one athlete are linked to the struggles of many; and they are insightful because of the things left unsaid. Media reports on highly successful Aboriginal athletes tend to focus on a very narrow set of factors that shape Aboriginal involvement in sport: the costs associated with sport in rural and remote areas (especially reserves), poverty, and discrimination. Moreover, these factors are usually highlighted whether or not they fit the athlete's biography, leaving a stereotype in place of better understanding. The lack of knowledge and awareness is a concern because existing data suggests that sport is inaccessible and inequitable for most, including urban Aboriginals whose sporting experiences are, at this point, invisible. Baseline data is needed so that a coordinated collective response to policy and program development can be created and implemented.

In the meantime, we can take sport more seriously by asking media about the varied experiences of elite Aboriginal athletes, rather than celebrating their accomplishments uncritically. Sport is important for the way it symbolically represents who participates in the nation and who is most engaged in community life. Misrepresentations in the media obscure the challenges that Aboriginal people face in gaining access to this important area of social life. Wouldn't it be nice if we could celebrate Aboriginal accomplishments in sport without glossing over and ignoring the broader complexities that lay at the heart of this matter? 


\section{Bibliography}

Aboriginal Affairs and Northern Development Canada. 2010. Fact Sheet-Urban Aboriginal Population in Canada. Ottawa: Government of Canada. Accessed 3 March 2014. http://www.aadnc-aandc.gc.ca/eng/1100100014298/1100100014302.

Bloom, M., M. Grant, and D. Watt. 2005. Strengthening Canada: The Socio-Economic Benefits of Sports Participation in Canada. Ottawa: The Conference Board of Canada, Education and Learning.

Canadian Heritage. 2005. Sport Canada's Policy on Aboriginal Peoples' Participation in Sport. Ottawa: Minister of Public Works and Government Services Canada.

-_- 2013a. Sport Definition Parameters. Accessed 2 March 2014. http://www.pch.gc.ca/ eng/1358281601198/1358281957233.

_-_. 2013b. "B-Ongoing Priorities." Federal/Provincial/Territorial Priorities for Collaborative Action 2007-2012. Accessed 2 March 2014. http://www.pch.gc.ca/eng/1374773566297.

Clark, W. Kids' Sports. Ottawa: Statistics Canada, Canadian Social Trends.

Coakely, J., and P. Donnelly. 2009. Sports in Society: Issues and Controversies. Second Canadian Edition. Toronto: McGraw-Hill Ryerson.

Forsyth, J., and M. Heine. 2008. "Sites of Meaning, Meaningful Sites?: Sport and Recreation for Aboriginal Youth In Inner City Winnipeg, Manitoba." Native Studies Review 17 (2): 99-113.

Forsyth, J., and V. Paraschak. 2013. "The Double Helix: Aboriginal People and Sport Policy in Canada." In Sport Policy in Canada, ed. L. Thibault and J. Harvey, 267-93. Ottawa: University of Ottawa Press.

Gruneau, R. 2010. Trends in Community Sport Participation and Community Sport Organizations Since the 1990s: Implications for West Vancouver. Toronto: Centre for Sport Policy Studies.

Halas, J., H. McRae, and A. Carpenter. 2013. “The Quality and Cultural Relevance of Physical Education for Aboriginal Youth: Challenges and Opportunities." In Aboriginal Peoples and Sport in Canada: Historical Foundations and Contemporary Issues, ed. J. Forsyth and A. Giles, 182-205. Vancouver: UBC Press.

Ifedi, F. 2008. Sport Participation in Canada, 2005. Ottawa: Statistics Canada, Culture, Tourism, and the Centre for Educational Statistics Division.

MacIntosh, D., and D. Whitson. 1990. The Game Planners: Transforming Canada's Sport System. Montreal and Kingston: McGill-Queen's University Press.

Morrow, D. and D. Wamsley. 2013. Sport in Canada: A History. Don Mills: Oxford University Press.

Paraschak, V., and Forsyth, J. 2010. "Aboriginal Women 'Working' at Play: Canadian Insights." Ethnologies 32 (1): 157-73.

- - - 2011. "Invisible but Not Absent: Aboriginal Women, Knowledge Production and the Restructuring of Canadian Sport." In Sport, "Race" and Ethnicity: Narratives of Diversity and Difference, ed. D. Adair and S. Pope, 219-34. Morgantown: Fitness Information Technology, University of West Virginia Press. 
Sport Canada. 2003. Report on Consultations with Provincial/Territorial Aboriginal Sport Bodies on the Draft Policy Framework. Ottawa: Sport Canada.

Sutcliffe, J. 2002. Participation in Sport in Canada: Baseline Data and Barriers to Participation. Ottawa: Federal-Provincial Territorial Sport Committee Working Group.

Tewksbury, M., and A. Arsenault. 2014. After the 2010 Vancouver Games Expectations are High for Canadian Athletes. The Current, CBC, podcast audio. Accessed on 2 March 2014. http://www.cbc.ca/thecurrent/popupaudio.html?clipIds=2435425753,2435424714. 